
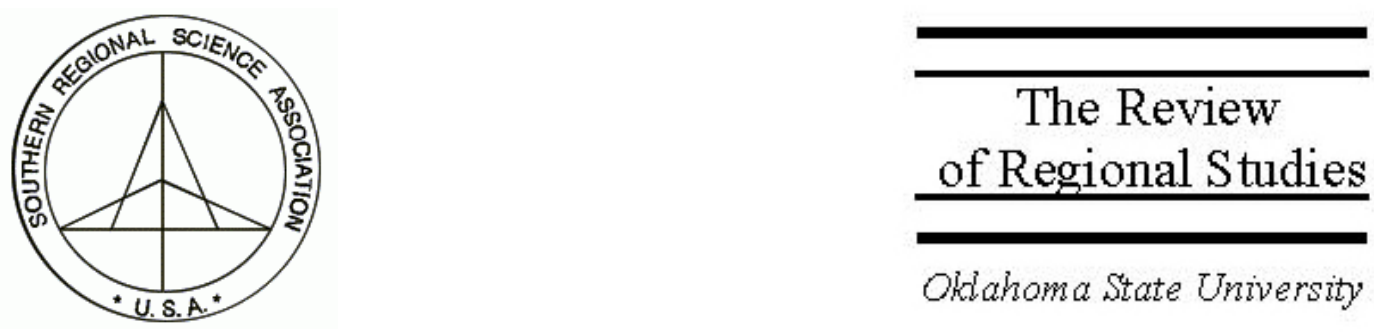

\title{
Spatial Effects of European Integration: Do Border Regions Benefit Above Average?
}

\author{
Annekatrin Niebuhr \\ IAB Nord, Regional Research Network of the Institute for Employment Research, \\ Projensdorfer Straße 82, D-24106, Kiel, Germany, e-mail: annekatrin.niebuhr@iab.de
}

\begin{abstract}
A basic result of new economic geography (NEG) models is that the proximity to consumer markets impacts wages and employment within regions. The ongoing process of European integration, being targeted on the reduction of barriers to trade and factor mobility, has presumably changed relative market access in Europe. The present paper aims to provide some evidence on spatial effects of integration caused by declining border impediments and changing market potentials. The analysis is based on a three-region economic geography model. We focus on the impact of integration on European internal border regions and the question of whether they realise above average integration benefits. The empirical analysis concerns integration effects in the EU15 regions arising from a reduction of non-tariff and other barriers since the mid 1970s.
\end{abstract}

Keywords: New economic geography; Market access; European integration; Border regions

JEL classification: C21; F15; R12

I would like to thank participants of the Congress "New Economic Geography - Closing the Gap Between Theory and Empirics" at HWWA Hamburg for useful comments on an earlier version of this paper. I am particularly grateful to Marius Brülhart and Silvia Stiller for valuable suggestions and to Carsten Schürmann for the generous provision of travel time data. I also thank an anonymous referee and the editor for helpful comments and suggestions. Financial support from the Fritz Thyssen Stiftung is gratefully acknowledged as part of the project "Border Regions, Border Impediments and European Integration." 


\section{INTRODUCTION}

Spatial effects of economic integration have been a central topic of regional science for decades. Against a background of continuing economic integration in Europe, the issue of spatial integration effects is a timely and highly relevant subject for policy at the national and EU level. In this context, most analyses focus on the question of whether integration involves increasing regional disparities. The EU Commission is also concerned about the development of lagging peripheral areas and border regions in the EU. In particular, regions between new and old EU countries and between Eastern European member states lag behind the EU average with respect to infrastructure endowment and economic restructuring. The Commission (2001a, b) notes that regions, especially those along the former external EU border, might be facing very pronounced integration effects because of their proximity to the new member states. In principle, border regions are expected to benefit from economic integration in the medium and long term. Intensified cross-border interaction might give rise to a dynamic growth process in border regions. However, in the short run border regions might face significant adjustment pressure due to increased competition in product and labour markets.

The objective of this paper is to provide empirical evidence on spatial effects of European integration with a special focus on border regions. Several studies have investigated the impact of integration on the spatial structure of economic activity in the EU based on market access considerations. Studies by Clark, Wilson, and Bradley (1969) and Keeble, Owens, and Thompson (1982) analyse corresponding effects of tariff reductions. However, the specific meaning of market access and of changes in market access due to integration for regional development remains vague in these studies because the theoretical basis of their analyses is weak. Trade in the EU has been essentially free of tariffs since the late 1960s. But significant barriers to cross-border trade remain due to differences in technical standards or bureaucratic impediments. The Single European Act aimed at a completion of the internal market in 1992 via a reduction of non-tariff barriers to trade.

This paper concentrates on effects resulting from declining non-tariff and other impediments to cross-border interaction. New economic geography (NEG) acts as a theoretical framework for this investigation because corresponding models establish a link between market access and regional development. NEG offers arguments why market access might be a decisive factor with respect to spatial integration effects, in particular if the impact on border regions is concerned. Based on corresponding approaches, Krugman and Venables $(1990,1993)$ investigated the implications of integration for the spatial structure of economic activity in Europe. A recent model by Brülhart, Crozet, and Koenig (2004) results in specific conclusions for border regions. But theoretical analyses alone do not provide clear-cut answers with respect to whether the economic core in Europe benefits from integration at the expense of the periphery.

We estimate the relationship between market access, per capita income, and employment using a NEG framework. The regression results are applied in a simulation analysis, 
the basic idea of which is that a reduction of border impediments due to integration affects the accessibility of markets in Europe. Changes in the market potential of EU regions will in turn impact regional income and employment. The study deals with the question of whether EU integration via its impact on market access has altered the spatial distribution of economic activity in the EU15. More precisely, we focus on whether border regions realized above-average integration benefits due to their favourable access to foreign markets. Our simulation analysis cannot provide a comprehensive investigation of spatial integration effects because we only consider changes in market access. We do not allow for effects resulting from differences in specialization, comparative advantages, and factor mobility in our investigation.

The rest of the paper is organized as follows. Section 2 comprises a short description of the theoretical framework of the study. We refer to traditional location theories and outline a three-region NEG model that determines integration effects in border regions. In Section 3, the regression model and the simulation methodology are presented. Data and the regional system are described in Section 4. The results of the simulation analysis are presented in Section 5. Section 6 concludes.

\section{THEORETICAL FRAMEWORK}

NEG models provide arguments regarding specific integration effects in border regions based on changes in regional market access. Access to foreign markets might act as a force resulting in an uneven spatial distribution of economic activities within countries even without exogenous location advantages or disadvantages. Changes in market access emerge in the course of integration processes due to declining border impediments. ${ }^{1}$ Over 50 years ago, Lösch (1944) discussed similar effects of integration. He developed a system of spatial market areas that are affected by national borders. Borders divide market areas and negatively affect a firm's market potential. Regions close to a border have comparatively small market areas, discouraging firms from locating in these areas. Consequently, border regions are marked by a relatively low density of economic activities in a pre-integration stage. Lösch described border regions as deserts, as wastelands in which many products can only be obtained from a distance or not at all. According to van Houtum (2000), border regions are generally regarded as marginal spaces disadvantaged by their peripheral location and divided market areas resulting in limited possibilities for economies of scale. Reversing this reasoning suggests that integration, i.e., the opening of a border for trade and factor mobility, may significantly change the economic situation of border regions. The reduction of border impediments decreases access costs with respect to foreign markets, especially in border regions. The accessible market area, i.e., the market potential of regions, rises especially in the geographical centre of an integrating area due to declining border impediments. An above-average increase in the market potential should raise the attractiveness of

\footnotetext{
${ }^{1}$ For a more detailed presentation of different models of location theory and their implication with respect to spatial integration effects, see Niebuhr and Stiller (2004).
} 
corresponding locations as production sites and should foster the development of the regional economy.

NEG models might also serve as a means to investigate spatial integration effects because they deal with the distribution of economic activities across space, which depends on the relative strength of centripetal and centrifugal forces. Centripetal forces arise from the fact that a relatively large home market has a positive impact on a firm's profit and a consumer's utility. This goes back to backward and forward linkages related to production and consumption. Scale economies and transport costs generate demand linkages between and within regions. These demand linkages contribute to agglomeration of economic activity and population. Locations that can supply a large local market at low transport costs are attractive for firms.

Integration via its impact on transport costs affects the balance of centripetal and centrifugal forces and thus might alter the spatial distribution of economic activities. The location of economic activities changes from strongly inward oriented to more outwardoriented. The domestic market becomes less important, possibly resulting in a reallocation of resources from previous centres to new locations. ${ }^{2}$ Market size considerations based on NEG models suggest that central regions, i.e., regions along the common border of integrating countries, might realize above-average integration benefits because they achieve above-average increases of their market potential. The relative geographical position of these regions is altered dramatically by integration, changing from a peripheral one on a national scale to a central one in the common market. However, most NEG models do not yield precise conclusions because integration might not be sufficient to destabilize the existing spatial distribution of economic activity. Moreover, integration might work to the advantage of central locations or peripheral areas. ${ }^{3}$ Finally, only a few approaches, such as the model by Brülhart, Crozet, and Koenig (2004), deal explicitly with the impact of integration on the spatial allocation of economic activity within countries by considering an internal spatial structure of an integrating economy.

\subsection{A Three-Region NEG Model}

In this section, we outline a three-region NEG model by Brülhart, Crozet, and Koenig (2004) that addresses the issue of integration effects in border regions. ${ }^{4}$ In this model, there are three regions in two countries, the domestic country and the foreign economy (0). The domestic country comprises an interior region (1) and a region that shares a common border with the foreign country, i.e., the border region (2). The regional economies consist of a monopolistically competitive industry and a perfectly competitive agricultural sector. Goods are traded among all regions.

\footnotetext{
${ }^{2}$ See Fujita et al. (1999).

3 See, e.g., Krugman and Venables $(1990,1993)$.

${ }^{4}$ The model is a three-region version of Pflüger's (2004) NEG model, which represents an analytically solvable version of Krugman's (1991) core-periphery model.
} 
Tastes of all consumers are described by a quasi-linear utility function:

(1) $U=\gamma \ln C_{M}+C_{A}$ with $\gamma>0$

where $C_{A}$ is the quantity of the agricultural product consumed, and $C_{M}$ is a composite of symmetric product varieties given by:

$$
C_{M}=\left[\sum_{k=1}^{K} \frac{\sigma-1}{c_{k}^{\sigma}}\right]^{\frac{\sigma}{\sigma-1}}
$$

$\sigma$ is the constant elasticity of substitution between any pair of varieties, and $K$ is the number of varieties. Consumers have a love for variety. With increasing $\sigma$, the substitutability among varieties rises, thus the desire to spread consumption over manufactured goods declines. Utility is maximized subject to the budget constraint:

$$
Y=C_{A} p_{A}+\sum_{k=1}^{K} c_{k} p_{k}
$$

where $Y$ is income, and $p_{A}, p_{k}$ are prices of the agricultural product and variety $k$ of the manufactured commodity, respectively. Utility maximization results in the following demand function for manufactured goods. ${ }^{5}$

$$
c_{i j}=\frac{\gamma\left(p_{i} T_{i j}\right)^{-\sigma}}{P_{j}^{1-\sigma}} ; i, j=1,2,3
$$

$c_{i j}$ is demand in region $j$ for manufactured goods produced in region $i . P_{j}$ is the price index for manufactured goods in region $j, p_{i}$ is the mill price of varieties produced in $i$, and $T_{i j}$ are transport costs. Manufactured goods are traded among regions incurring iceberg transport costs, i.e., a fraction of any product shipped melts away and only a part $\left(1 / T_{i j}\right)$ arrives at its destination. The price of varieties produced in $i$ and sold in $j,\left(p_{i} T_{i j}\right)$, therefore, consists of mill price and transport costs. ${ }^{6}$ The approach differentiates between cross-border transport costs $\left(T_{01}, T_{02}\right)$ and internal transport costs $\left(T_{12}\right)$, which apply to interregional domestic trade. It is assumed that the border region has better access to the foreign market $\left(T_{01}>T_{02}\right)$.

In the model by Brülhart, Crozet, and Koenig (2004), there are two factors of production: mobile human capital $H$ and immobile labour $L$. In agriculture, only labour is used as an input, whereas the manufacturing sector uses both labour and human capital. By choice of units, the price of the agricultural product $p_{A}$ equals the wage of farm labour $w_{A}$.

5 We omit the variety subscript $k$ because of the symmetry of all varieties produced in region $i$.

6 In contrast, trade of the agricultural product is assumed to incur no trade costs. 
Moreover, $w_{A}=1$, since the agricultural product serves as a numéraire. In contrast, there are increasing returns in the production of each individual variety of manufactured goods due to fixed costs. Each manufacturing firm has the same production function in which labour and human capital enter as inputs. Total costs are given by:

$$
T C_{i}\left(c_{k}\right)=r_{i} H_{i}+L_{i} c_{k}
$$

where $r_{i}$ is the compensation of human capital. Fixed costs arise from the use of human capital in the production of variety $k$, whereas marginal costs are due to labour input. The price of a variety produced in $i$ is given by a mark-up on marginal costs:

$$
p_{i}=\left(\frac{\sigma}{\sigma-1}\right) \text {. }
$$

Because of increasing returns, each variety is only produced by one firm in one region. Thus regions do not produce the same set of products but differentiated bundles of manufactured goods. The number of corresponding varieties is proportional to human capital of the region. If human capital increases due to immigration, the number of supplied manufactured goods will rise. There is no international factor mobility. However, human capital is mobile between domestic regions. Human capital owners migrate towards the region that offers highest utility. Migration takes place according to the following indirect utility differential.

$$
V_{i}-V_{j}=\gamma \ln \left(P_{j} / P_{i}\right)+\left(r_{i}-r_{j}\right) \quad i, j \neq 0
$$

Thus, there are two factors determining the mobility of human capital. Human capital owners migrate towards regions characterized by a relatively low price index for manufactured goods and a comparatively high remuneration of human capital.

\subsection{Spatial Effects of Integration}

In the model by Brülhart, Crozet, and Koenig (2004), economic integration among two countries, i.e., a decline of cross-border transport costs, gives rise to two opposing forces. ${ }^{7}$ On the one hand, a rising accessibility of the foreign market increases the incentive to locate near foreign consumers for the domestic industry, i.e., to locate in the border region, because the importance of domestic demand declines relative to foreign demand. The strength of the centripetal force related to domestic purchasing power declines in the course of integration. Domestic agglomeration is also weakened due to the increasing weight of foreign supply for domestic consumers. Therefore the border region also gains attractiveness for mobile human capital owners because foreign supply of consumer goods becomes more important. On the other hand, integration will result in

${ }^{7}$ We only consider the impact of trade liberalization and ignore effects resulting from free crossborder movement of labour and human capital. 
increased competition by foreign firms, especially in border regions, that reduces the attractiveness of border regions as production sites.

Thus, integration reduces the strength of both internal centripetal and centrifugal forces. According to Brülhart, Crozet, and Koenig (2004), the effect of integration on the centrifugal force dominates. Consequently, the probability that domestic manufacturing concentrates in one region increases due to declining external trade costs. If we assume perfect symmetry of domestic regions, the corresponding location of industry will be indeterminate. However, if the border region has better access to foreign demand, its attractiveness relative to the internal domestic region will rise in case of trade liberalization. A concentration of manufacturing in the interior region is only possible when a comparatively large number of manufacturing firms were located in that region in the pre-integration period. From the perspective of the border region, the beneficial impact of an improved accessibility of foreign demand dominates the adverse effect of increased competition by neighbouring foreign firms.

\section{REGRESSION AND SIMULATION FRAMEWORK}

The empirical analysis of integration effects comprises several stages. First we estimate the relationship between regional economic activity, measured by per capita income and employment density, and market access for a cross-section of Western European regions. Second, regional market access is calculated applying the distance decay parameter estimated on the first stage of our analysis. Moreover, we determine market potentials for different integration scenarios using estimates of border impediments between European countries. Finally, changes in market access, regional per capita income, and employment due to declining border impediments are determined in order to investigate regional integration effects.

\subsection{Regression Model}

The point of departure of our regression analysis is the so-called nominal wage equation used frequently in empirical studies investigating the relevance of NEG models and the existence of a spatial wage structure for different cross sections ${ }^{8}$ :

$$
w_{j}=\left[\sum_{i=1}^{J} Y_{i} e^{-\tau(\sigma-1) d_{i j}} P_{i}^{\sigma-1}\right]^{1 / \sigma}
$$

with $w_{j}$ as the nominal wage in region $j, Y_{i}$ as income in region $i . \tau$ is transport costs per distance unit, and $d_{i j}$ is the distance (travel time) between the regions $i$ and $j$. According to equation (8), the nominal wage level in region $j$ depends on a weighted sum of

8 See Hanson (2000); Brakman, Garretsen, and Schramm (2002); Mion (2003); and Niebuhr (2006) for corresponding analyses. 
purchasing power in all accessible regions $i$, whereby the weighting scheme is a function declining with increasing distance between locations $i$ and $j$. As Hanson (2000) notes, equation (8) can be thought of as a spatial labour demand function. Labour demand and wages are relatively high in locations close to high consumer demand. Regional wages increase with income of neighbouring regions and decline with rising transport costs to these locations. In the context of the model described in Section 2, wage refers to the remuneration of mobile human capital owners.

As data on regional prices are not available for European regions, we have to assume that the price index is equal in all regions $\left(P_{i}=P\right)$. This implies that nominal instead of real market access is considered. Nominal market access is frequently used in empirical studies that investigate implications of NEG. Moreover, we use GDP per capita and employment density as proxies for regional economic activity in region $j\left(z_{j}\right)$, taking into account that market access is a main determinant of the spatial structures of both employment and factor prices. Wage data, the preferred data, are not available for the cross section under consideration. The corresponding regression model is given by:

$$
\log \left(z_{j}\right)=\alpha_{0}+\alpha_{1} \log \left(\sum_{i=1}^{J} Y_{i} e^{-\alpha_{2} d_{i j}}\right)+\varepsilon_{j}
$$

Equation (9) is a fairly restricted explanation of regional disparities. There are probably more factors that affect the spatial distribution of employment and per capita income such as local amenities. In order to deal with these issues and to check whether the determined relationships between market access and economic activity are robust, control variables are included in the regression models. Control variables comprise indicators for sectoral composition of regional economies and the presence of local amenities as well as dummies for countries and outlying regions if necessary.

\subsection{Simulation Analysis}

We apply the coefficients $\alpha_{1}$ and $\alpha_{2}$, derived from the estimation of the model given by equation (9), for a cross section of European regions in order to calculate market potentials, their change due to declining border impediments, and resulting effects on per capita income and employment. The analysis deals with effects resulting from changes in market access due to integration among Western European countries since the mid 1970s. Thus, we are mainly interested in changes of the market potential, not in its absolute amount. Only purchasing power of Western European regions is taken into account in the simulation analysis. Income of the Central and Eastern European countries (CEEC) is not included in the market potential. ${ }^{9}$

${ }^{9}$ Brülhart, Crozet, and Koenig (2004) analyze the spatial impact of enlargement via a similar methodology, focusing on the effects resulting from the emerging accessibility of purchasing power of the CEECs. 
Integration is modelled via a manipulation of the travel time matrix and specification of the weighting scheme for income in the market potential formula, respectively. Interregional travel time data by Schürmann and Talaat (2000), used in the regressions and the simulation analyses, contain specific border impediments because cross-border travel time includes waiting times at border crossings. A full integration scenario would be based on this travel time matrix with no waiting times because border impediments are zero in this case. To reproduce the integration process since the mid 1970s, we add travel time equivalents for non-tariff barriers that decline during the analyzed period from 1975 to 2000 (see Section 4.2 for details).

The market potential of region $j$ in year $t$ is given by:

$$
M P_{j t}=\sum_{i} Y_{i t} \cdot e^{-\alpha_{2}\left(d_{i j}+b_{i j t}\right)}
$$

where $Y_{i t}$ is income in region $i$ in year $t, \alpha_{2}$ is the distance decay parameter determined in the regression analysis, and $d_{i j}$ is the travel time between the regions $i$ and $j . b_{i j t}$ are estimates of border impediments in year $t$, given as travel time equivalents. According to equation (10), the market potential of region $j$ is the weighted sum of purchasing power in all accessible regions $i$, whereby the weighting scheme is a function declining with increasing distance and other impediments between locations $i$ and $j .{ }^{10}$ Border impediments caused by institutional and administrative disparities, cultural and linguistic differences as well as social or psychological barriers are captured by $b_{i j t} . b_{i j t}=0$, if $i$ and $j$ are located in the same country. $b_{i j t}$ will be approximated by estimated impediments if the regions $i$ and $j$ are located in two different EU member states.

Regional effects of integration between $t_{0}$ and $t_{1}$ are estimated by using information on the intensity and evolution of border impediments in Europe:

$$
\begin{aligned}
\log \left(\frac{z_{j t_{1}}}{z_{j t_{0}}}\right) & =\alpha_{1}\left[\log M P_{j t_{1}}-\log M P_{j t_{0}}\right] \\
& =\alpha_{1}\left[\log \sum_{i} Y_{i t_{1}} \cdot e^{-\alpha_{2}\left(d_{i j}+b_{i j t_{1}}\right)}-\log \sum_{i} Y_{i t_{0}} \cdot e^{-\alpha_{2}\left(d_{i j}+b_{i j t_{0}}\right)}\right]
\end{aligned}
$$

The overall change $\log \left(z_{j t_{1}} / z_{j t_{0}}\right)$ caused by the change in market access can be partitioned into the effect of reduced border impediments and the effect resulting from the development of regional income. In order to isolate the effect of declining border impediments, the change in $z$ is determined for given regional income as well.

\footnotetext{
${ }^{10}$ Border impediments in terms of waiting times at border crossings are contained in the travel time $d_{i j}$.
} 


$$
\begin{aligned}
\log \left(\frac{z_{j t_{1}}}{z_{j t_{1} *}}\right) & =\alpha_{1}\left[\log M P_{j t_{1}}-\log M P_{j t_{1} *}\right] \\
& =\alpha_{1}\left[\log \sum_{i} Y_{i t_{1}} \cdot e^{-\alpha_{2}\left(d_{i j}+b_{i j t_{1}}\right)}-\log \sum_{i} Y_{i t_{1}} \cdot e^{-\alpha_{2}\left(d_{i j}+b_{i j t_{0}}\right)}\right]
\end{aligned}
$$

Results are compared for different types of regions - internal border regions, regions along external EU borders, and non-border regions - in order to investigate whether internal border regions achieve above-average integration benefits. Changes in regional market access, per capita income, and employment are estimated for the periods 19752000, 1985-2000, and 1990-2000 because data availability has increased during the period under consideration. First, this allows us to check the robustness of results, which is important because we had to generate some of the data for 1975 and $1985 .^{11}$ Second, increasing data availability enables us to apply an extended and more adequate cross section to analyze integration effects in different regional categories in the 1990-2000 period.

\section{DATA AND REGIONAL SYSTEM}

\subsection{Variables}

Dependent variables in the regression analysis are log per capita Gross Value Added (GVA) and log employment density (number of employees per $\mathrm{km}^{2}$ ), respectively. The regression model is estimated with data for 1975, 1980, 1985, 1990, 1995, and 2000. The dependent variables are given for 158 European regions. Regional income, i.e., purchasing power, is approximated by GVA in 205 European regions. Indicators for the sectoral composition of regional economies are based on GVA data by NACE-CLIO R6 classification (agricultural, forestry and fishery products, manufactured products, building and construction, market services, non-market services). The corresponding GVA shares, i.e., the percentages of regional GVA in agriculture, manufacturing, etc., are used as control variables. The data were taken from the European regional databank of Cambridge Econometrics. Information on local amenities (e.g., length of the seashore, mean annual sunshine radiation, concentration of cultural sites) used as additional controls were taken from the databank generated in the course of the Study Programme on European Spatial Planning (SPESP). ${ }^{12}$

\subsection{Distance Measurement, Size and Development of Border Impediments}

Distance is measured by travel time in minutes between the centers of the regions. A specific problem refers to the internal distances of the regions that enter into the market potential formula. Internal distance is modelled as proportional to the square root of the

\footnotetext{
${ }^{11}$ See Appendix for details.

12 See Bundesamt für Bauwesen und Raumordnung (eds.): Study Programme on European Spatial Planning. Final Report. Forschungen 103.2.- Bonn 2001.
} 
area of the region. ${ }^{13}$ We determine the internal distance of region $i$ in minutes of travel time as:

$$
d_{i i}=0.75 \cdot \sqrt{A_{i}}
$$

where $A_{i}$ denotes the area of region $i$ in $\mathrm{km}^{2}$.

The generation of border impediments $\delta_{i j t}$ rests upon estimates of bilateral trade barriers between European countries for the year 1994 by Bröcker (1998). According to the results, factors by which international trade is reduced compared with intranational trade range between 7 and 117 among European countries. On average, trade declines by a factor of 34 due to crossing a national border. Analyses by Nitsch (2000) as well as Head and Mayer (2000) provide information on the evolution of border impediments in the EU between the late 1970s and the mid 1990s. Their findings suggest that border impediments have decreased by around 30 to 50 percent since the late $1970 \mathrm{~s}$. We combine the estimates of bilateral trade impediments in 1994 with the available information on the development of border impediments in the EU since the 1970s in order to generate data on bilateral border effects in 1975, 1985, 1990, and 2000. For our simulation analysis, we assume a steady decline of reduction factors of international trade by 50 percent between 1975 and 2000. In Table 1, averages of the bilateral border impediments are summarized for the countries under consideration. The figures for 1994 refer to the original estimates by Bröcker (1998). The impediments for 1975 and 2000 are generated by combining these estimates with the available information on the change of trade barriers among European countries since the 1970s.

The travel time equivalent of the border impediment $\delta_{i j t}$ is given by ${ }^{14}$ :

$$
b_{i j t}=\log \left(\delta_{i j t}\right) / \tau
$$

where $\tau$ is transport costs per distance unit. $\delta_{i j t}=1$ for regions $i$ and $j$ located in the same EU country. With respect to foreign regions, $\delta_{i j t}>1$, if the regions $i$ and $j$ are located in two different EU member states marked by significant border impediments. Since we have only information on trade barriers between countries, the travel time equivalents $b_{i j t}$ are the same for all pairs of regions $i$ and $j$ belonging to the same country pair. ${ }^{15}$ Our estimates for the coefficient of distance $\alpha_{2}=\tau(\sigma-1)$ range between 0.0037 and 0.0053 for per capita income (see also Section 5.1). Implied values for $\sigma$ vary between 5.4 and 5.8.

\footnotetext{
${ }^{13}$ This methodology is frequently applied in the corresponding literature. See, e.g., Head and Mayer (2000).

${ }^{14} \delta_{i j t}^{\sigma}$ is the reduction factor and $\left(\delta_{i j t}-1\right)$ is the tariff equivalent of border impediments (see Bröcker, 1998).

${ }^{15}$ To the best of our knowledge, there are no estimates of trade impediments on a sub-national level for the cross section under consideration.
} 
Niebuhr: Spatial Effects of European Integration

TABLE 1

Average Border Impediments 1975, 1994, and 2000 for European Countries

\begin{tabular}{lccc}
\hline & \multicolumn{3}{c}{ Reduction Factors of International Trade } \\
\cline { 2 - 4 } Country & 1975 & 1994 & 2000 \\
\hline Germany & 30.5 & 18.3 & 15.2 \\
France & 56.4 & 33.8 & 28.2 \\
Italy & 58.3 & 35.0 & 29.2 \\
Netherlands & 40.5 & 24.3 & 20.2 \\
Belgium & 40.6 & 24.4 & 20.3 \\
UK & 48.9 & 29.4 & 24.5 \\
Denmark & 73.5 & 44.1 & 36.7 \\
Greece & 56.1 & 33.6 & 28.0 \\
Finland & 52.7 & 31.6 & 26.4 \\
Sweden & 42.9 & 25.7 & 21.4 \\
Austria & 99.5 & 59.7 & 49.8 \\
Ireland & 48.9 & 27.0 & 24.5 \\
Luxembourg & 40.6 & 22.4 & 20.3 \\
Spain & 56.1 & 33.6 & 28.0 \\
Portugal & 56.1 & 33.6 & 28.0 \\
\hline Source: Bröcker (1998), own calculations. & \\
Notes: Figures for 1994 refer to estimates by Bröcker (1998), figures for 1975 and 2000 \\
are based on a calculation assuming that trade reduction factors decline by $40 \%$ between \\
1975 and 1994 and by 50\% during the entire period under consideration. There are no \\
estimates for Greece, Spain, Portugal, Ireland, and Luxembourg. For these countries the \\
average border effect is assumed or estimates for neighbouring countries are used (Ireland - \\
UK, Luxembourg - Belgium)
\end{tabular}

Therefore, with respect to the simulation of integration effects on per capita income, we assume $\tau=0.001 .^{16}$

\subsection{Regional System}

Within the framework of the analysis, three cross sections have to be distinguished. Two of them are relevant for the regression analysis: one cross section concerns the dependent variable and comprises $158 \mathrm{EU}$ regions. The second cross section consists of all regions the income of which is included in the market potential of the regression analysis, in total 205 European regions. These cross sections largely correspond with the NUTS 2 level. Exceptions include Denmark (3 former NUTS regions), Belgium, Germany (NUTS 1 level) and Sweden (NUTS 3 level). East German regions, Départements d'outre-Mer (France), Açores, Madeira (Portugal), Ceuta y Melilla, Canarias (Spain) are not considered because of data restrictions. Norway (19 Fylke) and Switzerland ( 7 Grossregionen) are included in the larger cross section for estimation of the

\footnotetext{
${ }^{16}$ Corresponding coefficient estimates for employment density differ: $\alpha_{2}$ ranges between 0.042 and $0.046, \sigma$ ranges between 3.1 and 4.3.
} 
market potential. With respect to the left-hand side of the regression model, Sweden, Norway, and Switzerland could not be considered because of data restrictions.

The calculation of market potentials only considers income in Western European regions. Market access is defined with respect to Western European markets because of severe data problems regarding Eastern European regions before the mid-1990s. Moreover, our analysis does not focus on the absolute level of the market potential. In fact, we are primarily interested in changes in market access due to a decline of border impediments between Western European countries. Therefore, we do not think that neglecting purchasing power of Eastern European regions will bias our results. For the simulation analysis, a third cross section is relevant. To ensure an adequate definition of border regions, fairly small observational units are chosen for the calculation of market potentials and the estimation of integration effects. The sample contains NUTS 2 and NUTS 3 regions and functional regions consisting of several NUTS 3 units. ${ }^{17}$ Integration effects are determined for three categories of regions: internal border regions, external border regions, and non-border regions. Internal border regions are defined as regions that share a common border with a foreign EU region. External border regions are those EU regions along the external EU border. We compare the results for internal border regions with effects acquired for non-border regions and border regions located at external EU borders.

\section{EMPIRICAL RESULTS}

\subsection{Regression Results}

The results of the regression analysis based on equation (9) for per capita income and employment density are summarized in Tables 2 and 3. Only estimates of the coefficients relevant for the simulation analysis and the years 1975, 1985, 1995, and 2000 are presented. In all regression models, control variables and dummies for outlying regions are included. ${ }^{18}$ The coefficients $\alpha_{1}$ and $\alpha_{2}$ are highly significant with expected signs. The results suggest that market access has a positive effect on per capita income and employment density of European regions. The estimates are fairly robust with respect to different years under consideration. However, there are some significant differences between the findings for GVA per capita and employment density. First, the impact of market access on employment seems to increase over time, whereas the corresponding coefficient is more or less unchanged in the equation for GVA per capita. Second, there are pronounced differences between the two dependent variables with respect to the distance decay of spatial interaction. The coefficient $\alpha_{2}$ can be interpreted as a spatial discount factor that determines the changes in the weight of purchasing power with increasing travel time between regions. As regards employment, the intensity of demand linkages

\footnotetext{
${ }^{17}$ A more detailed description of this cross section is given in the appendix.

${ }^{18}$ Outlying regions are defined as those observations the standardized residuals of which exceed the value $|2.5|$. Additional unreported regressions refer to the years 1980 and 1990. Results for these years and the included control variables are available from the author upon request.
} 
declines much faster with increasing distance than for per capita income. In view of these differences, we apply different coefficients $\alpha_{1}$ and $\alpha_{2}$ in the simulation analysis of employment and per capita income. For a specific dependent variable we employ the average of the coefficients arising for different years.

TABLE 2

Regression Results for Market Potential Function - GVA Per Capita

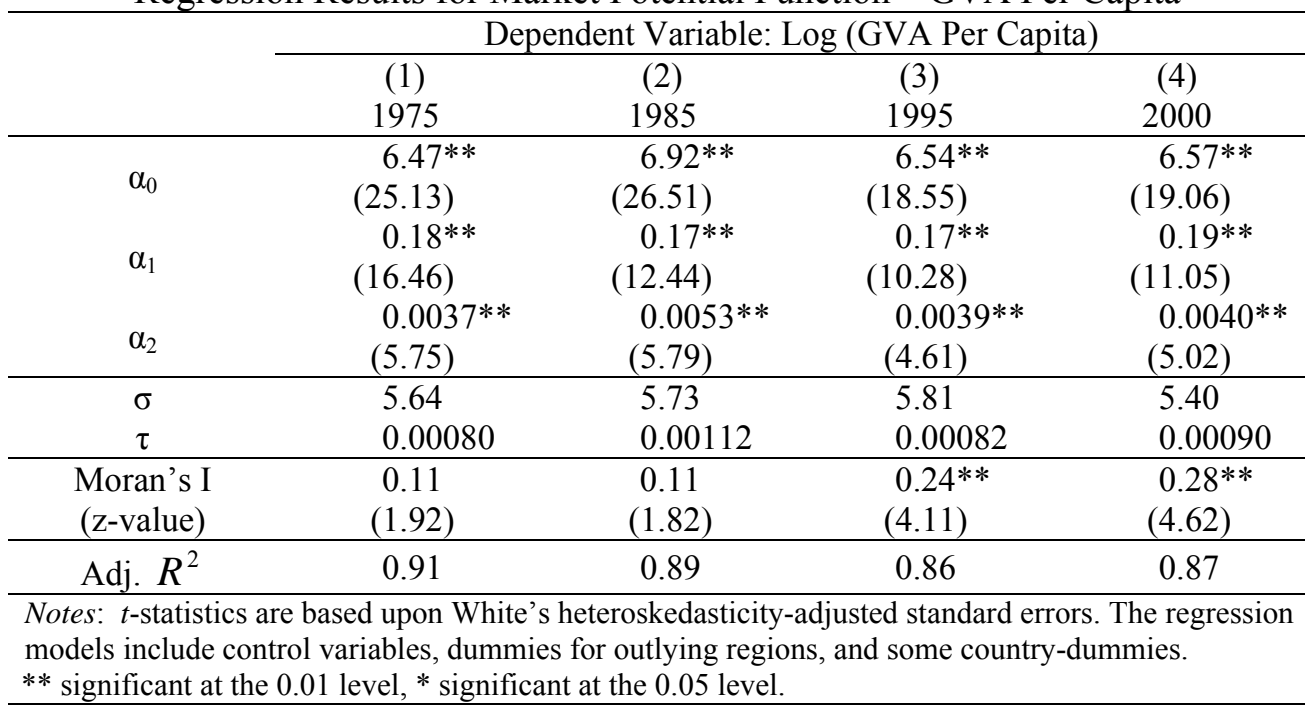

TABLE 3

Regression Results for Market Potential Function - Employment Density

\begin{tabular}{ccccc}
\hline & \multicolumn{3}{c}{ Dependent Variable: $\log \left(\right.$ Employees per $\left.\mathrm{km}^{2}\right)$} \\
& $(1)$ & $(2)$ & $(3)$ & $(4)$ \\
& 1975 & 1985 & 1995 & 2000 \\
\hline$\alpha_{0}$ & $2.97 * *$ & $2.59 * *$ & $2.22^{* *}$ & $2.01 * *$ \\
& $(6.76)$ & $(4.36)$ & $(4.04)$ & $(3.26)$ \\
$\alpha_{1}$ & $0.23^{* *}$ & $0.27^{* *}$ & $0.31 * *$ & $0.32^{* *}$ \\
& $(6.16)$ & $(5.50)$ & $(6.63)$ & $(6.37)$ \\
$\alpha_{2}$ & $0.0462^{* *}$ & $0.0432^{* *}$ & $0.0426^{* *}$ & $0.0418^{* *}$ \\
$\sigma$ & $(5.82)$ & $(5.56)$ & $(6.64)$ & $(6.28)$ \\
\hline$\tau$ & 4.31 & 3.69 & 3.25 & 3.08 \\
Moran's I & 0.01397 & 0.01604 & 0.01892 & 0.02006 \\
\hline z-value) & $0.12^{*}$ & $0.17^{* *}$ & $0.13 *$ & $0.13 *$ \\
\hline Adj. $R^{2}$ & $(2.01)$ & $(2.82)$ & $(2.16)$ & $(2.22)$ \\
\hline
\end{tabular}

Notes: $t$-statistics are based upon White's heteroskedasticity-adjusted standard errors. The regression models include control variables, dummies for outlying regions, and some country-dummies. ** significant at the 0.01 level, * significant at the 0.05 level. 
We also apply nonlinear instrumental variables estimation to address possible endogeneity, i.e., right-hand side variables, such as regional income might not be exogenous, potentially causing inconsistent estimates. Historical data on regional GVA and population, lagged by 10 years, are used as instruments for contemporary income. Unreported results of nonlinear instrumental variable regressions closely resemble the nonlinear least squares (NLS) results summarized in Tables 2 and 3 if we choose starting values close to the NLS coefficients. We also test for spatial error autocorrelation and estimate spatial econometric models in case of a misspecification as indicated by spatially autocorrelated residuals. ${ }^{19}$ Results of Moran's $I$ test on spatial autocorrelation in Tables 2 and 3 indicate that the regression models are misspecified due to ignored spatial effects, at least for specific years. In order to check the consequences with respect to the coefficient of market access, spatial error and spatial lag models are estimated as well. We only refer to estimates of the spatial error models because they achieve a better fit than the spatial lag models. In the spatial approach, the coefficient of market access ranges between 0.15 and 0.18 for per capita income as dependent variable. As regards the spatial model for regional employment density, estimates vary from 0.21 and 0.28 , also increasing in the course of time as observed for the corresponding NLS results. So the differences between spatial estimates and coefficients of the NLS regressions are fairly small. Altogether, this suggests that taking into account the spatial autocorrelation does not change the implications regarding the relevance of the market potential with respect to per capita income and employment. ${ }^{20}$

\subsection{Spatial Integration Effects}

In this section, we analyze the change of market access caused by the European integration and the associated impact on regional per capita income and employment in the EU15. In Table 4 some simulation results for market potentials with low and high distance decay are summarized. The high distance parameter corresponds with coefficient estimates for employment density as the dependent variable, whereas the low distance parameter applies to the findings for per capita income. Changes in market access in Table 4 refer to the 1975/1985-2000 period. In the following, we focus on the 1985-2000 period. According to the findings, market access of EU15 regions rose on average by 50 percent since the mid-1980s if we assume the low distance decay (44.2 percent for the high distance decay). However, one should not pay too much attention to the absolute level of integration effects since the simulation is based on estimates of border impediments and their development. Therefore, we lay emphasis on the relative performance of different groups of regions. In line with the theoretical prediction, internal border regions will show a more rapid growth of market potential than non-border regions and areas along external EU borders when we assume a low distance parameter. As the partition of corresponding effects reveals, this above-average development of internal border regions is primarily due to the relatively pronounced impact arising from declining border impediments: 10.4 percent for internal border regions compared with 4.5 percent in non-

\footnotetext{
${ }^{19}$ A binary contiguity matrix was applied as a spatial weights matrix.

${ }^{20}$ Unreported regression results are available from the author upon request.
} 
TABLE 4

Estimated Changes in Market Access 1975/1985-2000

\begin{tabular}{|c|c|c|c|c|}
\hline & \multicolumn{4}{|c|}{ Average Percentage Changes } \\
\hline & \multicolumn{2}{|c|}{$\begin{array}{c}\text { Market Potential } \\
\text { (low distance parameter) }\end{array}$} & \multicolumn{2}{|c|}{$\begin{array}{c}\text { Market Potential } \\
\text { (high distance parameter) }\end{array}$} \\
\hline & $1975-2000$ & $1985-2000$ & $1975-2000$ & $1985-2000$ \\
\hline \multicolumn{5}{|l|}{ Overall Effect } \\
\hline Non-border & 86.1 & 48.8 & 76.7 & 44.4 \\
\hline Internal border & 96.6 & 53.7 & 76.8 & 43.0 \\
\hline External border & 82.5 & 45.4 & 87.1 & 50.1 \\
\hline \multicolumn{5}{|c|}{ Effect of Regional Income Growth } \\
\hline Non-border & 78.4 & 44.2 & 76.7 & 44.4 \\
\hline Internal border & 78.6 & 43.3 & 76.8 & 43.0 \\
\hline External border & 78.4 & 43.0 & 87.1 & 50.1 \\
\hline \multicolumn{5}{|c|}{ Effect of Reduced Border Impediments } \\
\hline Non-border & 7.7 & 4.5 & $4.0 \cdot 10^{-9}$ & $3.2 \cdot 10^{-9}$ \\
\hline Internal border & 18.0 & 10.4 & $6.3 \cdot 10^{-8}$ & $5.0 \cdot 10^{-8}$ \\
\hline External border & 4.1 & 2.4 & $4.2 \cdot 10^{-11}$ & $3.3 \cdot 10^{-11}$ \\
\hline
\end{tabular}

border regions and 2.4 percent in external border regions. The low integration effects in external border regions are due to their peripheral location with respect to the European integration area. In contrast, differences among the groups are fairly small for effects caused by regional income growth.

However, the evidence of group-specific integration effects on market access change dramatically when the simulation analysis rests upon the high distance decay determined for employment density. The highly localized spatial extent of demand effects associated with the distance parameter implies that changes in market access caused by integration are negligible. As indicated by the results in columns 4 and 5 in Table 4, overall growth of market potential is almost completely caused by regional income growth. The impact of integration is virtually zero. The reduction of border impediments has no important effect on market potential. The rapid decline of demand linkages with increasing travel time involves a persistent irrelevance of foreign purchasing power for domestic employment growth. We cannot detect any significant impact of integration on regional employment.

In contrast, regional per capita income is affected by decreasing border impediments according to our findings. On average, per capita income of EU15 regions grew by 7.6 percent due to changes in market access between 1985 and 2000, applying the low distance decay. Systematic differences between border and non-border regions are evident for the change in per capita income induced by integration and corresponding growth of market access (see Figure 1). The impact of rising market potential on per 
capita income ranges between 7.0 percent for external and 8.0 percent for internal border regions. However, the effects directly caused by declining border impediments only amount to 1.3 percent increase of per capita income in internal border regions. The induced rise in per capita income is still smaller in non-border and external border regions -0.6 percent and 0.3 percent, respectively.

The findings for the 1975-2000 period are characterized by the same general pattern. Altogether, internal border regions are marked by an above-average development of accessible purchasing power and related growth of per capita income because of the impact of integration. This implies that the assumptions regarding the decline of border impediments impact the size of integration effects but not the spatial pattern. ${ }^{21}$ A decline of border impediments by 50 percent, as assumed for the period 1975-2000, results in an average increase of the market potential by 10 percent and a change of per capita income by almost 1 percent. Between 1985 and 2000 we assume a reduction of border impediments by roughly 37 percent. This gives rise to an increase in market access by 5.9 percent and growth of per capita income by 0.7 percent. Thus, with respect to per capita

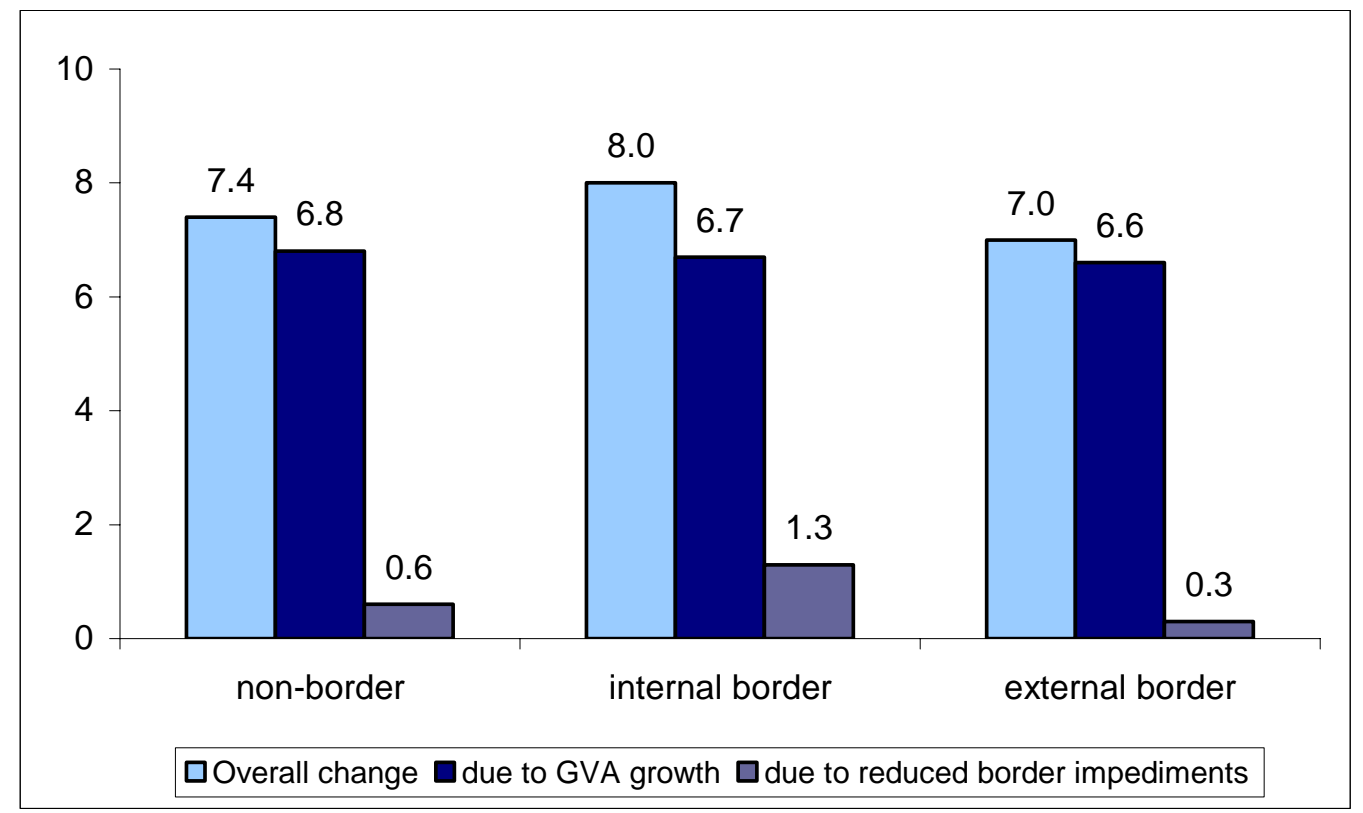

FIGURE 1. Change in GVA Per Capita Induced by Changes in Market Access $1985-2000$ (in \%)

Source: Own calculations based on data from Cambridge Econometrics regional data bank.

\footnotetext{
${ }^{21}$ There is a strong positive correlation (Pearson coefficient above 0.9) between the regional changes in market potential for the two periods under consideration.
} 
income, we may conclude that internal EU border regions realize above-average integration effects due to their locational advantages. It is important to keep in mind that changes in market access are caused by both reduced border impediments and development of regional purchasing power, and only a part of the underlying development of market access can be directly assigned to the integration process, although regional income growth, i.e., the change in regional purchasing power, is probably affected by integration as well.

The findings for the 1975/1985-2000 period are confirmed by simulation results for 1990-2000 (see Table 5). Thus, for the extended cross section that allows a more accurate demarcation of border regions, above-average integration benefits of internal border regions again can be observed. However, there is an interesting deviation regarding regions located along external EU borders. It seems that external border regions increasingly lag behind other EU regions with respect to the development of accessible purchasing power and corresponding income growth. In contrast to the empirical evidence for the 1975/1985-2000 period, the development of market access of external border regions is below average because both changes due to regional disparities in income growth and integration effects add to the relatively unfavourable performance of external border regions.

We also calculate country-specific effects (see Figure 2). The resulting pattern suggests that, aside from differences between border and non-border regions, there is a

TABLE 5

Estimated Changes in Market Access and Effects on Regional Per Capita Income 1990-2000

\begin{tabular}{lcc}
\hline & \multicolumn{2}{c}{ Average Percentage Changes } \\
& $\begin{array}{c}\text { Market Potential } \\
1990-2000\end{array}$ & $\begin{array}{c}\text { Per Capita GVA } \\
1990-2000\end{array}$ \\
\hline Overall Effect & 24.6 & 4.0 \\
Non-border regions & 29.0 & 4.7 \\
Internal border regions & 19.7 & 3.3 \\
External border regions & & \\
Effect of Regional Income Growth & 22.2 & 3.7 \\
Non-border regions & 22.7 & 3.7 \\
Internal border regions & 19.1 & 3.2 \\
External border regions & & \\
& & \\
Effect of Reduced Border Impediments & 2.4 & 0.4 \\
Non-border regions & 6.3 & 0.9 \\
Internal border regions & 0.6 & 0.1 \\
External border regions & & \\
Source: Own calculations based on data from Cambridge Econometrics regional data bank. \\
\hline
\end{tabular}




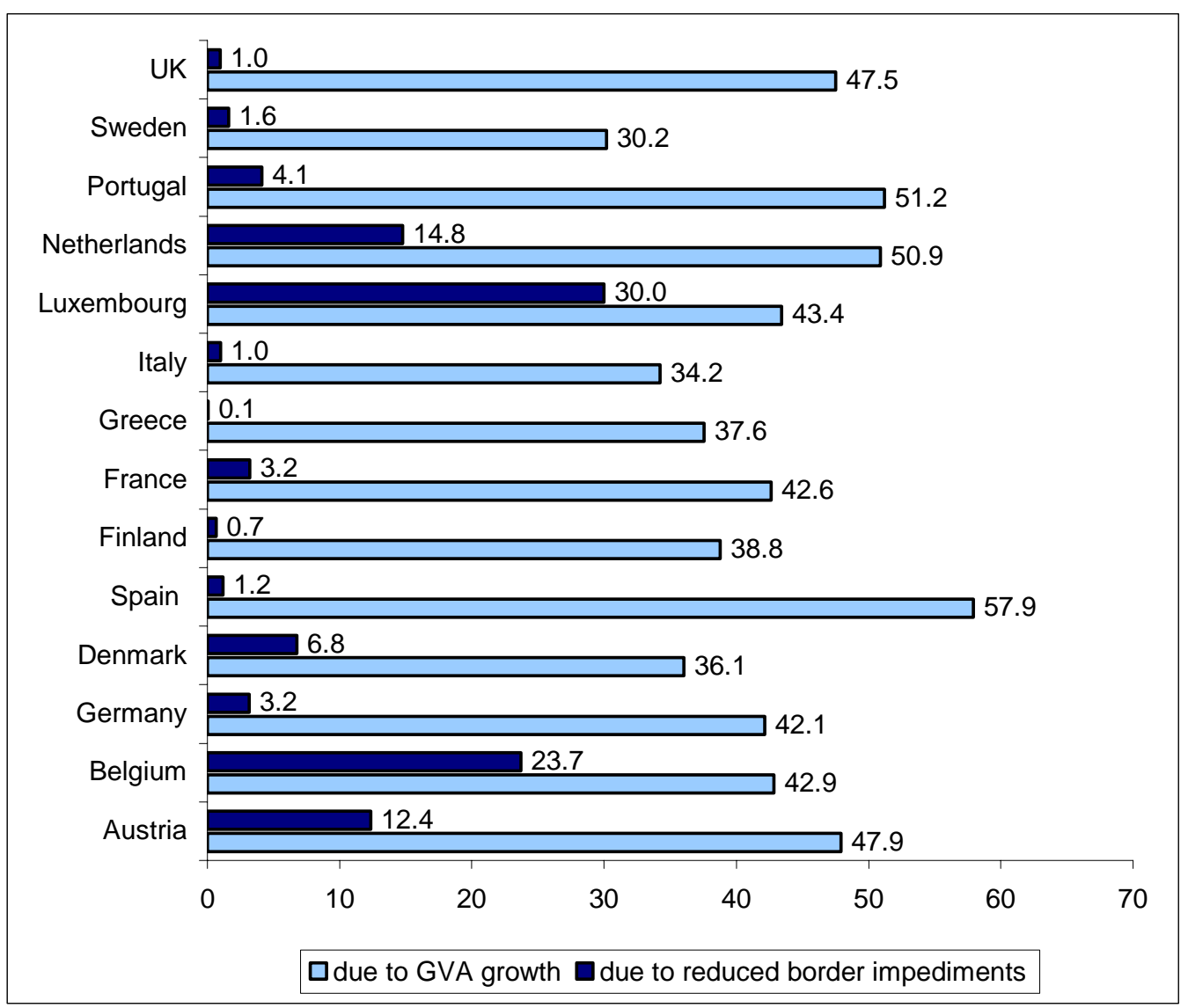

FIGURE 2. Change in Market Access in EU15 Countries 1985-2000 (in \%)

Source: Own calculations based on data from Cambridge Econometrics regional data bank.

second spatial dimension of integration effects on a larger European scale. The relation between changes in market access due to regional GVA growth and reduced border impediments varies significantly among EU15 countries. The weight of integrationinduced growth of market access relative to the effects caused by income growth is comparatively high for countries located in the centre of the European integration area, i.e., the Netherlands, Luxembourg, Belgium, and Austria. In contrast, the share of integration effects in the overall change in market potential is relatively small in peripheral member states such as Greece, Italy, and Finland. This is confirmed by an analysis that differentiates between central and peripheral regions on the European scale. Figure 3 shows average percentage changes in per capita income caused by changes in market access for three groups of regions: central and peripheral areas in Europe and an intermediate category labelled "other regions." We use the corresponding EU 


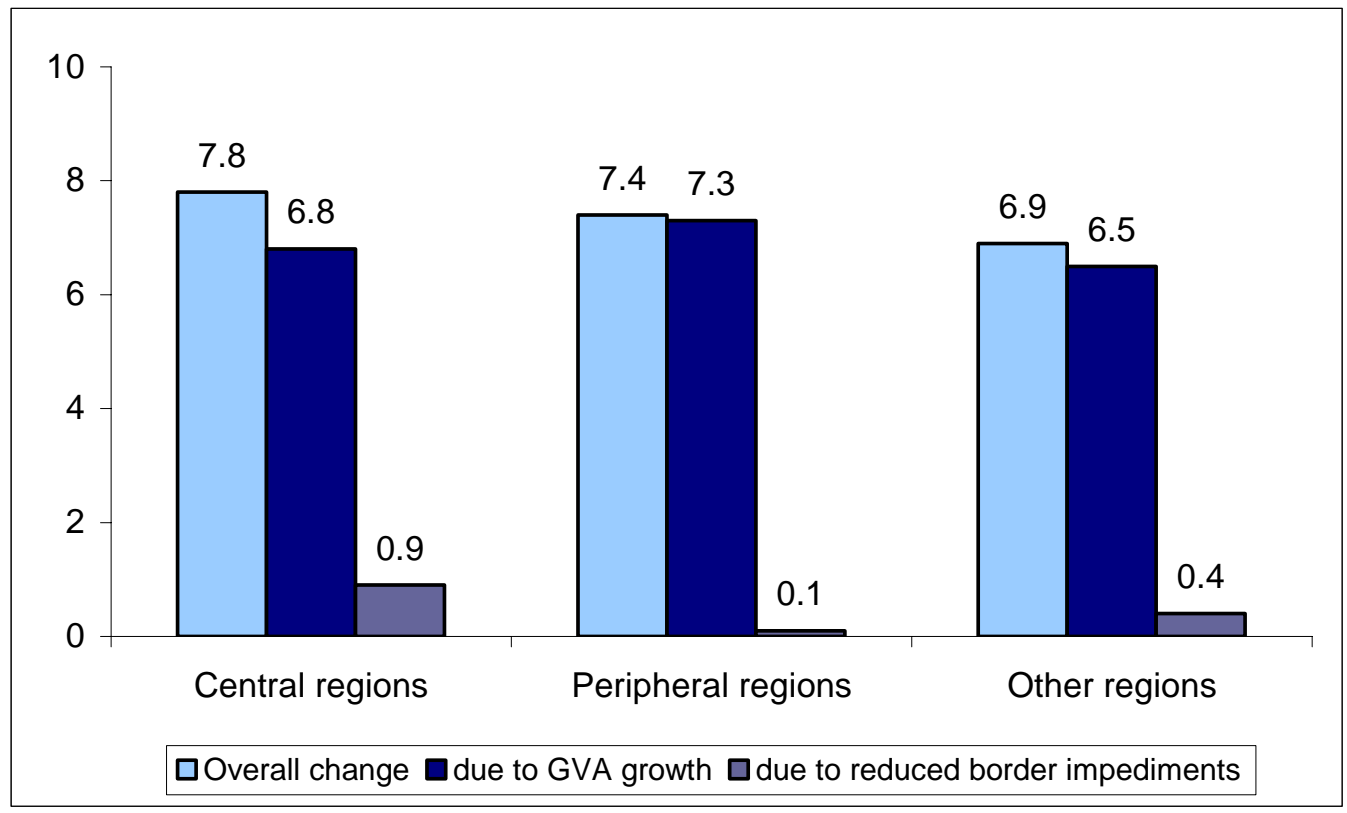

FIGURE 3. Change in GVA Per Capita Induced by Changes in Market Access 1985-2000 (in \%) - Centre versus Periphery

Source: Own calculations based on data from Cambridge Econometrics regional data bank.

classification presented in the second report on economic and social cohesion. ${ }^{22}$ As Figure 3 reveals, the intensity of integration benefits declines as one moves from the centre of the EU to the periphery. Thus, to sum up, the impact of integration on market access and per capita income has a spatial dimension in a twofold manner: on the European level, the benefits of declining border impediments increase as one moves from the periphery to the centre. However, they will decrease if we move from peripheral to more central regions on the national scale, i.e., from internal border regions to non-border regions.

Finally, we check the robustness of the findings with respect to the level of spatial aggregation. The results might be affected by the Modifiable Areal Unit Problem (MAUP). The simulation results could be sensitive to the number and relative size of the regional subdivisions. Due to data restrictions the cross sections used in the regression and the simulation analysis differ. In order to examine whether the results are influenced by the choice of the regional system, we also carry out the simulation analysis for the

$\overline{{ }^{22} \text { EU Commission (2001a), map A.4. }}$ 
cross section used in the regression analysis, a higher level of spatial aggregation. ${ }^{23}$ Previous findings are confirmed by the robustness check. The same ranking of region types emerges, with internal border regions realizing highest integration benefits followed by non-border and external border regions. The centre-periphery pattern of integration effects is also reproduced for this cross section. ${ }^{24}$

\section{CONCLUSIONS}

The findings of the simulation analysis suggest that integration benefits caused by declining border impediments systematically differ between border and non-border regions. In line with the prediction of a three-region NEG model, internal EU border regions achieve above-average integration effects due to their location in the centre of the European integration area. Since internal border regions are marked by a better access to the purchasing power of neighbouring EU member states, their attractiveness as production sites increases relative to non-border regions and areas along the external EU borders in the course of integration. However, according to the empirical evidence, the overall magnitude of corresponding integration effects is fairly small. Of course, the absolute magnitude of effects has to be interpreted with much caution. Moreover, the analysis considers only one specific effect of European integration. Other integration effects might work in an opposite direction as regards differences between border and non-border regions.

Furthermore, the sectoral composition of the regional economies might matter for strength of integration effects. Since border impediments are more relevant in the service sector than for manufactured products, regions specializing in tradable services might be exposed to more pronounced effects resulting from a reduction of trade barriers. ${ }^{25}$ Moreover, with respect to sector-specific integration effects, we also have to differentiate between tradable and non-tradable goods. This issue is important most notably for border regions because goods and services that are in principle non-tradables (e.g., consumer services, housing, and public transport) might become tradable goods in internal border regions due to the proximity of the foreign country. Therefore probably more branches are affected by integration in these areas compared to non-border regions. However, the decline of trade barriers implies increasing foreign demand and intensified competition (see Niebuhr and Stiller 2006). Thus, we suppose that the impact of integration is relatively strong in border regions, but we can not infer whether all branches benefit or lose. A comprehensive quantitative analysis of sector-specific effects is beyond the scope of the present paper and left for future research.

\footnotetext{
${ }^{23}$ We have to keep in mind that it becomes increasingly difficult to adequately define border regions as the average size of regions rises. For example, on the NUTS 1 level almost all regions in Germany share a common border with an EU country. Therefore, in case of such large regions we only classify a region as a border regions if a significant percentage of the total area is located along a border.

${ }^{24}$ Corresponding results are available from the author upon request.

${ }^{25} \mathrm{I}$ am grateful to a referee for making this point.
} 
With respect to differences in integration benefits on the European scale, our findings are in line with early studies by Clark, Wilson, and Bradley (1969) and Keeble, Owens, and Thompson (1982). They investigate effects of European integration by analyzing changes in regional accessibility induced by a reduction of tariff barriers. Their results point to a widening of regional disparities in market access. Enlargement as well as faster growth of more accessible regions tended to favour central areas in Europe in the 1960s and 1970s. The empirical evidence provided by our analysis suggests as well that the benefits of declining border impediments increase as one moves from the periphery to the centre of the EU. However, the positive impact of integration will diminish simultaneously if we move from peripheral to more central regions at the country level.

Regarding integration policy, regional policy, and concerns of the EU Commission that border regions might face very pronounced adjustment pressure due to integration, we have to keep in mind the different time horizons that matter in this context. Based on our analysis we can not draw conclusions on short- and medium-term effects in border regions and corresponding needs for EU policy. Our results have implications for the long-run growth prospects of regions. According to our findings, the Commission should pay special attention to the regions along the external borders of the EU because they are more likely to face problems due to their unfavourable access to purchasing power in the European integration area. Of course, we have to take into account that other integration effects and initial conditions might favour some external border regions. However, with respect to market access, the development of cross-border interaction along external EU borders is nevertheless a highly relevant issue in the policy context. This applies especially to poor Eastern European regions along the new external EU frontier.

\section{REFERENCES}

Brakman, S., H. Garretsen, and M. Schramm, 2002. "New Economic Geography in Germany: Testing the Helpman-Hanson Model," HWWA Discussion Paper No. 172, Hamburg.

Bröcker, J., 1998. "How Would an EU-Membership of the Visegrád-Countries Affect Europe's Economic Geography?” Annals of Regional Science 32, 91-114.

Brülhart, M., M. Crozet, and P. Koenig, 2004. "Enlargement and the EU Periphery: The Impact of Changing Market Potential," The World Economy 27, 853-875.

Bundesamt für Bauwesen und Raumordnung, 2001. Study Programme on European Spatial Planning," Final Report. Forschungen 103.2, Bonn.

Clark, C., F. Wilson, and J. Bradley, 1969. "Industrial Location and Economic Potential in Western Europe," Regional Studies 3, 197-212.

Commission of the European Communities, 2001a. "Unity, Solidarity, Diversity for Europe, its People and its Territory, Second Report on Economic and Social Cohesion, Luxembourg.

Commission of the European Communities, 2001b. "On the Impact of Enlargement on Regions Bordering Candidate Countries," Community Action for Border Regions, Brussels 
Commission of the European Communities, 2002. "First Progress Report. On the Impact of Enlargement on Regions Bordering Candidate Countries," Community Action for Border Regions, Brussels.

Hanson, G.H., 2000. "Market Potential, Increasing Returns, and Geographic Concentration," University of Michigan and NBER (revised version of NBER Working Papers 6429).

Head, K. and T. Mayer, 2000. "Non-Europe: The Magnitude and Causes of Market Fragmentation in the EU," Weltwirtschaftliches Archiv 136, 284-314.

Keeble, D., P.L. Owens, and C. Thompson, 1982. "Regional Accessibility and Economic Potential in the European Community," Regional Studies 16, 419-432.

Krugman, P., 1991. "Increasing Returns and Economic Geography," Journal of Political Economy 99, 483-499.

Krugman, P. and A.J. Venables, 1990. "Integration and the Competitiveness of Peripheral Industry," in C. Bliss (ed.), Unity with Diversity in the European Economy: The Community's Southern Frontier. Cambridge University Press: Campbridge, MA, pp. 56-77.

, 1993. "Integration, Specialization, and Adjustment," NBER Working Paper No. 4559, Cambridge, MA.

Lösch, A., 1944. Die Räumliche Ordnung der Wirtschaft, $2^{\text {nd }}$ Edition, Stuttgart.

Mion, G., 2003. "Spatial Externalities and Empirical Analysis: The Case of Italy," Journal of Urban Economics 56, 97-118.

Niebuhr, A., 2006. "Market Access and Regional Disparities: New Economic Geography in Europe," Annals of Regional Science 40, 313-334.

Niebuhr, A. and S. Stiller, 2004. "Integration Effects in Border Regions - A Survey of Economic Theory and Empirical Studies," Review of Regional Research 24, 3-21. , 2006. "Integration and Labour Markets in European Border Regions," Journal for Labour Market Research 39, 57-76.

Nitsch, V., 2000. "National Borders and International Trade: Evidence from the European Union," Canadian Journal of Economics 22, 1091-1105.

Pflüger, M., 2004. "A Simple, Analytically Solvable, Chamberlinian Agglomeration Model," Regional Science and Urban Economics 34, 565-573.

Schürmann, C. and A. Talaat, 2000. "Towards a European Peripherality Index: Final Report," Berichte aus dem Institut für Raumplanung, No. 53, Dortmund.

van Houtum, H., 2000. "Introduction: Current Issues and Debates on Borders and Border Regions in European Regional Science," in M. Velde and H. van der Houtum (eds.), Borders, Regions and People, European Research in Regional Science, No. 10, Pion, London, pp. 1-11. 


\section{APPENDIX}

\section{A1. Cross Sections}

Three cross sections are applied in the analysis. Two of them are relevant for the regression analysis: one cross section concerns the dependent variable and comprises 158 EU regions. The second cross section consists of all regions the income of which is included in the market potential, in total 205 European regions. With respect to the simulation analysis a third cross section is relevant. For the simulation of integration effects we mainly refer to the NUTS 3 level.

\section{EU15 - 498/612 Regions (NUTS 2, NUTS 3, Planning Regions)}

Belgium: 43 NUTS 3 regions

Denmark: 15 NUTS 3 regions

Germany: 74 planning regions (functional regions comprising several NUTS 3 regions)

Greece: 51 NUTS 3 regions

Spain: 48 NUTS 3 regions (excluding Ceuta y Melilla, Canarias)

France: 95 NUTS 3 regions (Corse on NUTS 2 level, excluding Départements d'outre-mer)

Ireland: 8 NUTS 3 regions (only considered 1990-2000)

Italy: 103 NUTS 3 regions (only 1990-2000 on NUTS 3 level, 1985-2000 NUTS 2 level)

Luxembourg: 1 region

Netherlands: 40 NUTS 3 regions

Austria: 35 NUTS 3 regions

Portugal: 28 NUTS 3 regions (only 1990-2000 on NUTS 3 level, 1985-2000 NUTS 2 level, excluding Açores, Madeira)

Finland: 13 NUTS 2 and 3 regions (Uusima and Etelä-Suomi on NUTS 2 level)

Sweden: 21 NUTS 3 regions

UK: 37 NUTS 2 regions

Norway: 19 fylke

Switzerland: 26 cantons

\section{A2. Data}

\section{Cambridge Econometrics Regional Data Bank (NUTS 2 Level)}

- Regional income: gross value added (GVA) 1975-2000

- Sectoral composition: shares of sectors in total GVA of region (NACE-CLIO R6 classification: agriculture, manufacturing, building and construction, market services, non-market services) 1975-2000

- $\quad$ Per capita income: GVA per inhabitant 1975-2000 
- Employment density: Employees per km² 1975-2000

\section{Eurostat Regio Data (NUTS 2 and NUTS 3 Level)}

- Gross domestic product (different length of regional time series, break in 1995)

- Employment (different length of regional time series, break in 1995)

$\bullet$

\section{Data from the Study Programme for European Spatial Planning (SPESP)}

- $\quad$ Seashore: Length of seashore in percentage of region's perimeter

- Sunshine: Mean annual sunshine radiation in $\mathrm{kWh} / \mathrm{m}^{2}$

- Emission: Emissions of acidifying gases - 3 classes

- Hazard: Natural hazards - 7 risk classes (earthquakes, volcanic activity, tidal waves, snow avalanches, slope instability)

- Protected areas: Designated or protected areas -5 classes

- Cultural sites: Number of registered monuments/cultural sites

- Density of cultural sites: Number of cultural sites by total area

- $\quad$ Tourist pressure: Ratio of yearly tourist stays by total resident population 1997/98

Missing regional data for Denmark and Norway was completed by data from the corresponding national statistical offices.

Data on regional income (GVA) is available for the entire period under consideration (1975-2000) only for the NUTS 2 level. Moreover, there is a break in the corresponding time series (GDP, GVA, employment) of Eurostat in 1995. In order to derive comparable data for the entire period under consideration, we use Eurostat data on NUTS 3 level to estimate NUTS 3 data based on NUTS 2 data from Cambridge Econometrics. Eurostat data on gross domestic product (GDP) for NUTS 3 regions is applied to construct shares of NUTS 3 regions in income of the corresponding NUTS 2 region. With these shares GVA of NUTS 2 regions is split in appendant NUTS 3 regions. For most countries income shares of NUTS 3 regions can be constructed back to the late 1970s or early 1980s. Where GDP data is not available on NUTS 3 level, the simulation analysis refers to the NUTS 2 level or the relevant country is excluded from the investigation. However, for the most recent period 1990-2000 all regions (see appendix) could be considered, since data availability on NUTS 3 level increased during the period under consideration. In the simulation for the periods 1975-2000 and 1985-2000, Ireland is excluded due to lack of data. For Portugal and Italy only NUTS 2 regions could be analyzed in this period. 